\title{
Entre a Escultura, Sensibilização e Investigação: a pelve como elemento mobilizador para a preparação poética e corporal do ator
}

\author{
Rodney Cardoso \\ Universidade Anhembi Morumbi \\ E-mail: rodneycardoso.online@gmail.com \\ Robson Lourenço \\ Universidade Estadual de Campinas \\ E-mail: lourencorobson@uol.com.br
}

Resumo

Este artigo reflete sobre o percurso poético e criativo desenvolvido dentro da pesquisa "O uso do centro do corpo para a percepção do trabalho do ator", de maio de 2017 a junho de 2018. De caráter exploratório, processual e qualitativo, este artigo apresenta as etapas de investigação através de um percurso metodológico de pesquisa em arte, que envolve procedimentos que mesclam escultura em argila, percepção corporal, experimentação e elaboração de partituras corporais com o intuito de desenvolver a composição cênica do solo "Caminho do Meio". Reflete sobre a relação entre os conhecimentos desenvolvidos através da investigação entre propriocepção e a percepção das estruturas ósseas da pelve como possível proposta para o trabalho de preparação corporal para o ator, de modo a ampliar seu repertório poético-criativo, com o intuito de compor narrativas para cenas teatrais.

Palavras-chave

Teatro. Preparação Corporal. Dramaturgia do Corpo. Anatomia Experiencial.
Abstract

This article ponders about the poetic and creative course as developed for the research named "The use of the body's center for the perception of an actor's work", from May 2017 to June 2018. Having an exploratory, procedural and qualitative character, the article presents the stages of the examination through a methodological route in art research, which involved procedures that mixed clay sculpture and the bodily perception of the pelvis, which in turn fostered the experimentation and elaboration of bodily scores with the purpose of developing the theatrical solo composition entitled "Caminho do Meio". It reflects on the relation between the pieces of knowledge that were developed through the investigation of the perception and proprioception of the human pelvis' bones structures as a possible proposal for an actor's work, when preparing his body in order to expand his poetic and creative repertoire, so as to compose narratives for theatrical scenes. Keywords

Theater. Bodily Preparation. Dramaturgy of the Body. Experiential Anatomy. 
O corpo possui extrema relevância nas artes cênicas e isso fica expresso na indagação de Lúcia Romano (2008, p. 17), quando a pesquisadora brasileira reflete: "[...] seria possível imaginar uma teatralidade onde a corporeidade do ator possa ser prescindida ou não mereça destaque?". A partir da reflexão de Romano, este artigo propõe o estudo do uso do centro do corpo ${ }^{1}$ na arte da cena e, consequentemente, sua relevância para a concentração da percepção voltada para o trabalho do ator.

Para o arcabouço da investigação a ser apresentada neste artigo há a integração de alguns procedimentos que partem da arte como pesquisa e envolvem: escultura em argila, elaboração de diários de bordo, laboratórios de investigação de movimento e períodos de composição voltados para a elaboração de uma cena teatral. Este conjunto de procedimentos interligados arquitetou um caminho metodológico que foi sedimentado a partir da reflexão sobre artistas que teorizam sua prática como caminhos de investigação. Os artistas que fundamentam os conceitos a serem apresentados neste artigo são Rudolf Laban² e Klauss Vianna ${ }^{3}$.

Laban entende como sendo o principal meio de expressão do indivíduo seu próprio movimento (Bonfitto, 2002). Sua análise para a expressividade corporal baseia-se no estudo do movimento a partir de quatro

\footnotetext{
1 Cabe ressaltar que nesta pesquisa o centro do corpo é estudado a partir da relação da estrutura óssea da pelve em relação às outras estruturas esqueléticas do pesquisador.

2 Rudolf Laban (1879-1958) - Nasceu na Bratislava, pertencente na época à Hungria (Laban, 1978). Experienciou diversas expressões artísticas, mas seu contato com o teatro ocorreu no ano de 1894. Na ocasião atuou como assistente de direção no teatro de Pozsony, na Hungria (Bonfitto, 2002).

3 Klauss Vianna (1928-1992) - Bailarino e coreógrafo, foi também pesquisador e professor, além de trabalhar como preparador e diretor corporal com atores. Desenvolveu trabalho significativo voltado ao movimento. Conjuntamente a sua esposa, Angel Vianna, Klauss Vianna foi precursor do termo "expressão corporal" e também do pensamento denominado "preparação corporal de ator" no Brasil (Neves, 2002).
}

fatores: Peso, Tempo, Espaço e Fluência. Sobre os fatores de movimento, a pesquisadora brasileira Lenira Peral Rengel reflete que pertencem:

[...] à própria natureza do fato de existir, o agente com eles se relaciona, de forma integral. Esta relação é aparente no movimento e se estrutura por meio da capacidade mental emocional/racional e física, de forma consciente ou não. (Rengel, 2001, p. 70)

Cada um destes fatores possui qualidades de esforço, aspectos próprios e podem ser combinados entre si. De acordo com Bonfitto (2002), para Laban o esforço é entendido como o impulso interno gerador do movimento e também como qualidade que resulta das combinações estabelecidas entre os diferentes fatores de movimento. É pertinente ao ator conhecer estes elementos e pesquisá-los por meio de ações corporais, com o intuito de construir repertório para a criação de partituras, que poderão ser utilizadas futuramente na elaboração de cenas. Segundo Laban:

O movimento humano com todas as suas implicações mentais, emocionais e físicas é o denominador comum à arte dinâmica do teatro. As ideias e sentimentos são expressos pelo fluir do movimento e se tornam visíveis nos gestos, ou audíveis na música e nas palavras. (Laban, 1978, p. 29)

Além das pesquisas para o movimento de Rudolf Laban, esta investigação também se apoia na reflexão do artista brasileiro Klauss Vianna. De acordo com Jussara Miller (2007) as estruturas do corpo humano e seu movimento atraíram o interesse de Klauss Vianna por quase quatro décadas.

Vianna relutou em sistematizar o próprio trabalho, por considerar que este sofreria constantes transformações a partir das 
experiências de cada pessoa que o estudasse (Neves, 2004). Os estudos realizados por Vianna foram sistematizados por uma parcela de seus seguidores a partir do que se nomeou Técnica Klauss Vianna ${ }^{4}$. Embora caracterizada como técnica, este modo de sistematização do pensamento de Vianna reconhece e respeita as particularidades de cada indivíduo. Como afirma Neide Neves:

Não há um modelo Klauss Vianna, uma estética determinada a priori, mas há corpos pensantes descobrindo sempre mais, a partir dos princípios desenvolvidos por ele. O movimento destes corpos, apesar de mostrar uma unidade técnica, guarda a sua individualidade. (Neves, 2004, p. 4-5)

A partir do conteúdo pesquisado dentro da pesquisa corporal proposta por Rudolf Laban e também a partir da sistematização do pensamento de Klauss Vianna, alguns conceitos serviram de base para a análise do processo de investigação "O uso do centro do corpo para a percepção do trabalho do ator". A partir do pensamento desenvolvido na Técnica Klauss Vianna, esta pesquisa embasa-se nos tópicos corporais apresentados por Jussara Miller (2007), como: presença, articulação e apoios. Tais conceitos integram o processo lúdico, fase introdutória apresentada por Miller para a compreensão da Técnica Klauss Vianna.

Do universo labaniano serão abordados neste artigo os fatores de movimento Tempo e Espaço (Laban, 1978; Rengel, 2001; Bonfitto, 2002). Entre eles podemos destacar o estudo corporal da cruz diagonal e da cruz tridimensional (Rengel, 2001); a investigação dos acentos rítmicos (Laban, 1978; Rengel, 2001); e também as trajetórias de

\footnotetext{
4 A Técnica Klauss Vianna foi estruturada didaticamente por Neide Neves e por Rainer Vianna, filho de Klauss Vianna e de Angel Vianna, entre os anos 1980 e início dos anos 1990 (Neves, 2004).
}

movimento (Rengel, 2001). Os conceitos aqui mencionados serão abordados mais à frente dentro deste artigo e serão descritos dentro do contexto do trabalho de investigação realizado, com o propósito de perceber o processo de pesquisa artística desenvolvido.

Possíveis horizontes de reflexão entre o esculpir e sensibilizar

A investigação debruçou-se inicialmente sobre a compreensão anatômica da pelve. Durante a realização deste processo de pesquisa em arte, o corpo e o foco na pelve não foram considerados como objetos de estudo distintos do sujeito de pesquisa, pois como esclarece Sônia Machado de Azevedo (2002, p. 135): "O que se trabalha é uma totalidade que pensa, sente, age; que é pensada, sentida, agida no fenômeno da interpretação".

E para desenvolver um relato das percepções desenvolvidas como artista ao longo da pesquisa e adquiridas durante a trajetória do fazer, optou-se por efetuar registros dos processos realizados através do desenvolvimento de diários de bordo, que foram utilizados como uma ferramenta metodológica para futura reflexão e desenvolvimento da pesquisa. Marina Marcondes Machado (2002) defende a utilização do diário de bordo:

[...] como algo fundamental nas pesquisas em Artes Cênicas que envolvam o trabalho em processo [...]; proponho tratar o Diário como um recurso filosófico e metalinguístico para o pesquisadorcriador, cuja finalidade principal seria a ampliação de um espaço meditativo da experiência vivida durante a pesquisa [...]. (Machado, 2002, p. 263) 
Registrar o que ocorreu no processo de pesquisa dentro do diário de bordo auxiliou na reflexão sobre os apontamentos da investigação e serviu também como inspiração para as cenas que seriam futuramente criadas. A releitura das anotações (incluindo considerações, dúvidas, trechos de livros pesquisados, desenhos e roteiros de ensaios) favoreceu uma análise mais objetiva, direcionando a outras reflexões. Isto corresponde à observação de Machado (2002), quando indica que o trabalho de registro do processo pode preceder a reflexão.

Devido ao caráter pessoal, subjetivo e, às vezes, confessional do conteúdo registrado, a escrita dos diários de bordo apresentou um formato que transitava entre conteúdos objetivos e poéticos. Em alguns momentos, ler o que havia sido escrito e da maneira como havia sido redigido durante $o$ processo de pesquisa, atualizava as investigações desenvolvidas durante o momento daquele relato e trazia à tona o imaginário das percepções vivenciadas pelo artistapesquisador e primeiro autor deste artigo. $\mathrm{E}$, ainda que a escrita possa parecer desconexa, ou carregada de um sentido particular, isso deve ser considerado como parte do processo do registro. Pois, como pontua Machado (2002, p. 262), "[...] as anotações de um Diário são extremamente pessoais e passam por uma teia de significação extremamente própria, partindo, sempre, do olhar do pesquisador".

Para apresentar uma camada desta teia de significação própria apresentada na reflexão de Machado, a seguir serão relatadas as etapas desenvolvidas dentro do processo de pesquisa, quando os relatos objetivos serão integrados às narrativas poéticas desenvolvidas nos diários de bordo ao longo da investigação. Os trechos escolhidos dentro dos diários são registros poéticos e serão apresentados em itálico com diagramação diferenciada do texto objetivo normalmente utilizado em artigos, com o intuito de integrar a pesquisa acadêmica ao desenvolvimento poético desta investigação.

\section{—Pelve em argila - Estrutura em molde}

\author{
Olho o passado \\ A fim de tocar as lembranças \\ E com isso \\ Tocar-me para um registro no presente ${ }^{5}$
}

Após o levantamento dos conceitos iniciais a serem estudados e já apresentados anteriormente neste artigo, a pesquisa foi encaminhada à fase seguinte, quando houve a confecção de uma escultura feita em argila a partir de uma estrutura óssea em resina da pelve. O processo foi realizado ao longo dos meses de maio a agosto de 2017.

O objetivo de esculpir a pelve não foi reproduzir fielmente o formato dos ossos da estrutura em resina que serviu como modelo. A escultura auxiliou o reconhecimento dos ossos da pelve para, posteriormente, esta ação ser aprofundada no processo de investigação corporal desenvolvido na pesquisa e que será apresentado adiante dentro deste artigo.

A seguir serão apresentadas em detalhes as etapas de percepção da estrutura óssea da pelve através do processo de escultura em argila e também as eventuais percepções desenvolvidas pelo artista-pesquisador através do seu diário de bordo.

Antes de entrar em contato com o bloco de argila foi estabelecida uma relação do artista-pesquisador com a prótese em resina da estrutura óssea da pelve, por meio de um toque cuidadoso e acurado. Através da ação de tocar a estrutura em resina da pelve foi possível identificar o seu peso e formato.

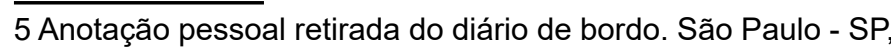
31.08.2017. 
Com a ponta dos dedos foram reconhecidas suas protuberâncias, cavidades e suas articulações.

Olhar a pelve por diversos ângulos e movê-la no espaço com as mãos desenvolveu caminhos para, posteriormente, esculpir em argila aquela estrutura do esqueleto. $O$ ato de experimentar posicionar a pelve sobre uma mesa possibilitou diferentes formas de olhá-la e depois esculpi-la. Destaca-se a seguir um trecho do diário de bordo do artista-pesquisador sobre o momento de observar a estrutura em resina da pelve antes de esculpi-la, quando o primeiro autor deste artigo pondera poeticamente: "Experimentar posicioná-la sobre a mesa de diferentes formas. Continuar explorando a peça e não saber por onde começar. Afigurá-la como espelho na busca de algum retorno, algum tipo de reflexo. E continuar em silêncio ${ }^{6 \prime}$.

A seguir apresentamos uma foto da estrutura óssea em resina plástica e outra com 0 ato de esculpir do artista-pesquisador, para posteriormente refletir sobre o processo de investigação:

Figura 1 - À esquerda, prótese em resina da estrutura óssea da pelve. À direita, artista-pesquisador em processo de escultura. Foto do Pesquisador.

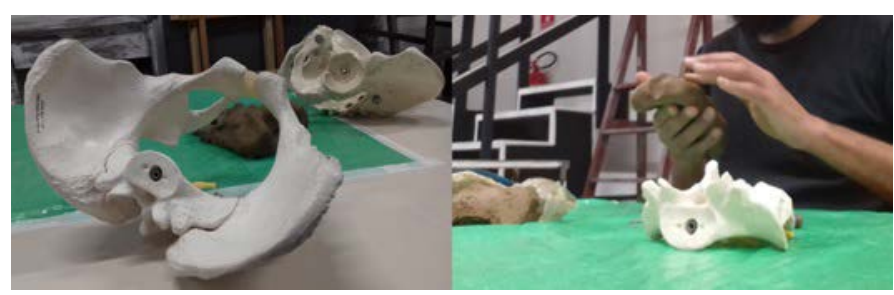

Fonte: Arquivo pessoal.

Solicita-se ao leitor que observe as fotos apresentadas anteriormente em conjunto com o poema desenvolvido pelo artista-pesquisador e apresentado a seguir. Ao perceber a imagem do artista-pesquisador durante $o$ ato de modelar, em conjunto com

6 Anotação pessoal retirada do diário de bordo. São Paulo - SP, 31.08.2017. a poesia retirada do diário de bordo, será possível apresentar os caminhos de percepção desenvolvidos pelo pesquisador neste primeiro encontro com $o$ ato de esculpir a estrutura da pelve:

Há poesia na argila
Que se desmancha
Para se integrar
Se despedaça
Para fortalecer
Há poesia na argila
No contato
No tato
No trato
O que eu vejo
Eu também toco
E me toca
E quando percebo
Transformo
Movo a argila
E me movo ao moldá-la.

Ressaltamos neste momento do artigo, as duas últimas frases do registro apresentadas anteriormente, pois ao mover e moldar a argila durante $o$ ato de esculpir foi possível o reconhecimento dos ossos da pelve dentro desta etapa da investigação. Esculpir a pelve fez com que se observasse a prótese com mais detalhes e culminou em uma melhor compreensão da estrutura óssea esculpida, através da integração dos sentidos do tato e da visão.

Convidamos o leitor a perceber as fotografias das esculturas resultantes do osso sacro em conjunto com a estrutura em resina observada. As imagens apresentadas poderão servir como base de reflexão sensível futura, quando o artigo ponderará como os atos de tocar e esculpir os ossos da pelve influenciaram os caminhos de sensibilização

7 Anotação pessoal retirada do diário de bordo. São Paulo - SP, 31.08.2017. 
e investigação do artista-pesquisador através do movimento.

Figura 2 - Sequência de fotos da prótese e escultura do osso sacro. Foto do pesquisador.

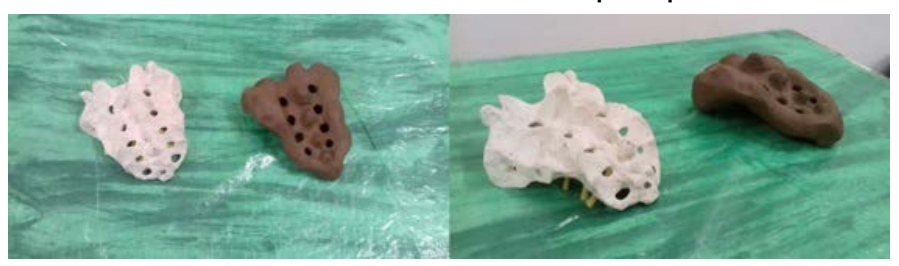

Fonte: Arquivo pessoal.

\section{Entre o esculpir e o ato de} sensibilizar: a ponta dos dedos como caminho de sensibilização

Se o olhar e o toque são solicitados durante 0 ato de modelar, pode-se supor que tanto a identificação como a compreensão amalgamam-se nesse processo. Sob a influência dessa produção de sentidos, é lançada a seguinte questão a quem lê: a escultura da pelve feita pelo artista-pesquisador poderia ser considerada futuramente como uma espécie de materialização da fusão dessas apreensões de sentidos? Os atos de esculpir e de olhar a pelve trariam algum patamar para o desenvolvimento futuro da pesquisa artística apresentada neste artigo?

Para começar a iniciar as reflexões em direção às perguntas levantadas, apresentaremos algumas etapas desenvolvidas dentro da pesquisa. Após o período em que 0 artista-pesquisador desenvolveu 0 ato de esculpir a estrutura da pelve em argila, a ponta dos dedos partiu para um período, onde a sensibilização da pelve era realizada através do toque do artista em seu próprio corpo.

O intuito deste autotoque na pelve tinha o objetivo de reconhecer esta porção corporal. Conforme Klauss Vianna (2005, p. 77), "Se o corpo não estiver acordado é impossí- vel aprender seja o que for". Por isso, antes de se iniciar a exploração do movimento é necessário um momento de sensibilização, com o intuito de despertar o corpo do artista-pesquisador durante o processo de investigação corporal.

Como o presente estudo trata da estrutura óssea da pelve, os procedimentos de sensibilização foram direcionados à região e consistiram no toque e no contato desta porção do corpo com o chão. Apresentamos abaixo um relato sobre o procedimento de sensibilização da pelve, desenvolvido a partir do diário de bordo, para posteriormente ponderarmos sobre ele:

\begin{abstract}
Deitado, com as costas no chão, inicio o procedimento de sensibilização pelo reconhecimento da articulação da sínfise púbica, com um toque firme e circular; depois vou para o osso ilíaco direito, continuo o toque até o púbis e depois toco o ísquio. Em seguida, repito o curso pelos ossos ilíacos, púbis e ísquio esquerdos. Geralmente, demoro-me neste contato, em decorrência do formato e tamanho desses ossos. Ao segurar as laterais e pressionar com os dedos polegares, em direção à parte interna da estrutura, saliento o aspecto côncavo dos ossos e imagino-me segurando no ar uma bacia de ossos ocupada pelas minhas vísceras. Depois, viro de bruços e toco o osso sacro e cóccix ${ }^{8}$.
\end{abstract}

Figura 3 - À esquerda, prótese e peça de escultura do osso do quadril direito. À direita, prótese e escultura do osso do quadril esquerdo. Foto do pesquisador.

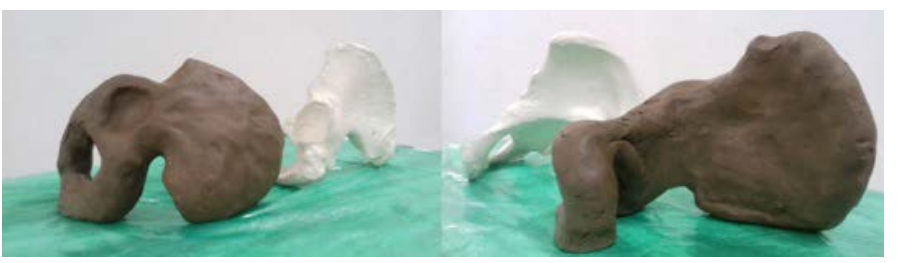

Fonte: Arquivo pessoal.

8 Texto elaborado a partir de anotação pessoal retirada do diário de bordo. São Paulo - SP, 19.09.2017. 
Para compreender este instante de silêncio e percepção profunda do artista-pesquisador durante o ato de tocar o osso do ilíaco em seu próprio corpo, pedimos licença ao leitor para apresentar o próximo trecho do artigo em primeira pessoa, para que o relato da experiência de sensibilização artística seja apresentado através da subjetividade, vivida naquele momento.

O toque no meu corpo foi apoiado na experiência anterior de esculpir em argila. Os ossos da pelve durante o processo de autossensibilização permearam o meu imaginário e no instante em que tocava meus próprios ossos, por cima da roupa, vinham à mente imagens da pelve no momento da escultura. A percepção desenvolvida durante 0 processo de esculpir em argila atualizava-se durante o toque no corpo nos laboratórios de autossensibilização.

Em algumas ocasiões, o toque de reconhecimento da estrutura óssea da pelve assemelhava-se ao toque empregado na ação de esculpir. Não suponho que o toque diretamente no corpo não dê conta do reconhecimento, mas compreendo que ao imaginar os ossos anteriormente esculpidos, enquanto tocava o meu próprio corpo, auxiliou e influenciou no processo de percepção da estrutura dos ilíacos e do sacro durante os laboratórios de sensibilização do corpo. Sobre o perceber e a fusão de imagens trago o pensamento de Sônia Machado de Azevedo (2002):

Perceber, ao contrário, é uma fusão instantânea, imediata, do sentir e de uma constatação desse mesmo sentir, não há separação e sim união: dados da realidade, colhidos pelo indivíduo; nesse sentido, a percepção é uma forma de conhecimento não racional. Por um lado, o mundo sentido, por outro, uma formalizaçã estruturação e transformação em conhecimento percebido. (Azevedo, 2002, p. 203)
Após a sensibilização, houve o contato com a superfície do chão através da experimentação entre os atos de deitar, rolar e sentar, quando diferentes estruturas da pelve também foram sensibilizadas através do contato com o solo. Segundo Miller (2007, p. 59): "O chão é um elemento primordial e a mais concreta referência para o aluno se observar e se perceber". É do encontro entre o chão e os ossos que surgem as percepções, e para mim, artista-pesquisador, esta relação com o solo foi muito significativa.

Quando me sensibilizo, torno-me mais consciente do aqui e agora, não só em relação ao meu corpo, mas também com o ambiente que me cerca. Sendo assim, é possível estabelecer um paralelo entre esse momento de sensibilização da pelve e o conceito de presença, um dos sete tópicos corporais que integram o processo lúdico da Técnica Klauss Vianna (Miller, 2007). Quando estava atento ao aqui e agora durante o ato de tocar o chão com os ossos da pelve, percebia se meu corpo estava dolorido, ou se havia alguma parte que eu queria mover mais ou atentar para porções da pelve que foram menos investigadas através do movimento.

A sensibilização convidava à atenção $e$ mantinha o corpo disponível durante os laboratórios de movimento, aspectos necessários para a fase de investigação proposta pelo artista-pesquisador. A seguir apresentaremos como tais laboratórios influenciaram a elaboração da cena teatral "Caminho do Meio", que será refletido a seguir neste artigo.

\footnotetext{
9 O solo teatral "Caminho do Meio" é composto por três cenas de narrativa não linear, que são: Pense no Parto; Caminho do Meio; e Mulher na Via.
} 


\section{Caminho do Meio - Caminho guiado pelos ossos}

Até o momento apresentamos as etapas de escultura em argila e o processo de sensibilização da pelve, em conjunto com a exploração inicial de movimentos desta porção corporal com o chão - através dos atos de deitar, rolar e sentar.

Após este processo de sensibilização, iniciava a exploração e levantamento de material criativo para o solo teatral "Caminho do Meio". O trabalho efetuado na sala de ensaio estruturou-se em três estágios: investigação do movimento a partir da liderança da pelve; improvisação a partir de partituras de movimento previamente levantadas; e composição da cena resultante da pesquisa.

Dentro do processo de investigação de movimento por parte do artista- pesquisador, houve o levantamento de possibilidades da relação da liderança do movimento a partir da pelve e seus possíveis direcionamentos integrados com o Fator Espaço, de Rudolf Laban. A interligação entre o movimento da pelve e o pensamento de Laban partiram de suas reflexões sobre os conceitos de cruz tridimensional e cruz diagonal, a partir das ponderações de Lenira Peral Rengel (2001).

Segundo Rengel (2001), a cruz tridimensional é estruturada em seis direções dimensionais: cima - baixo (comprimento); lado esquerdo - lado direito (amplitude); e frente - trás (profundidade). $O$ trabalho de pesquisa desenvolvido sobre este conceito foi investigado corporalmente de duas formas. Em uma delas o movimento do artista-pesquisador tinha como ponto de partida a pelve, que liderava o restante do corpo a partir das direções propostas pela cruz tridimensional. Em outro momento, a pelve do artista-pesquisador permanecia estável e eram investigados os movimentos dos braços e das pernas a partir da exploração das direções anteriormente relatadas neste parágrafo.

Ao comparar os resultantes dos movimentos pesquisados, nota-se que ao manter a pelve estável não houve a percepção da expansão da cinesfera ${ }^{10}$ do artista-pesquisador durante a exploração destes movimentos. O que é diferente quando o movimento parte da pelve, pois ela direciona e encaminha a coluna vertebral e o conjunto de costelas, possibilitando a investigação do tronco em direção ao espaço. Ao ponderarmos sobre isto, traremos a reflexão de Laban sobre a relação entre centro do corpo e extremidades:

Os movimentos que se originam do tron$\mathrm{co}$, do centro do corpo, e depois fluem gradualmente em direção das extremidades dos braços e pernas são em geral mais livremente fluentes do que aqueles nos quais o centro do corpo permanece imóvel quando os membros começam a se movimentar. (Laban, 1978, p. 47)

Além disso, quando o primeiro autor deste artigo se autopropunha que a pelve conduzisse o movimento em diferentes direções, notou-se alterações do esqueleto do artista-investigador como um todo. Percebeu-se a plasticidade de movimento existente entre o todo e a parte no próprio corpo do pesquisador, quando a estrutura da pelve foi autopercebida como móvel, flexível e pulsante.

Esta percepção da pelve pulsante e flexível reverberou nas investigações corporais do artista-pesquisador também no estudo da cruz diagonal (Rengel, 2001), quando as seguintes direções do corpo no espaço foram pesquisadas: alto-direita-frente, baixo-esquerda-trás, alto-esquerda-frente,

\footnotetext{
10 A cinesfera é explicada por Rengel (2001, p. 37) como "a esfera dentro da qual acontece o movimento. [...]. É a esfera de espaço em volta do corpo do agente no qual, e com o qual, ele se move."
} 
baixo-direita-trás, alto-esquerda-trás, baixo-direita-frente, alto-direita-trás e baixo-esquerda-frente.

A seguir apresentaremos algumas fotos tiradas durante o processo de investigação da pelve em relação à cruz diagonal e também durante a pesquisa corporal da cruz tridimensional, para posterior reflexão das propostas que foram desenvolvidas a partir deste estudo:

Figura 4 - Fotos de laboratórios de estudos da pelve em relação ao espaço. Foto de Enzo Frizzo.

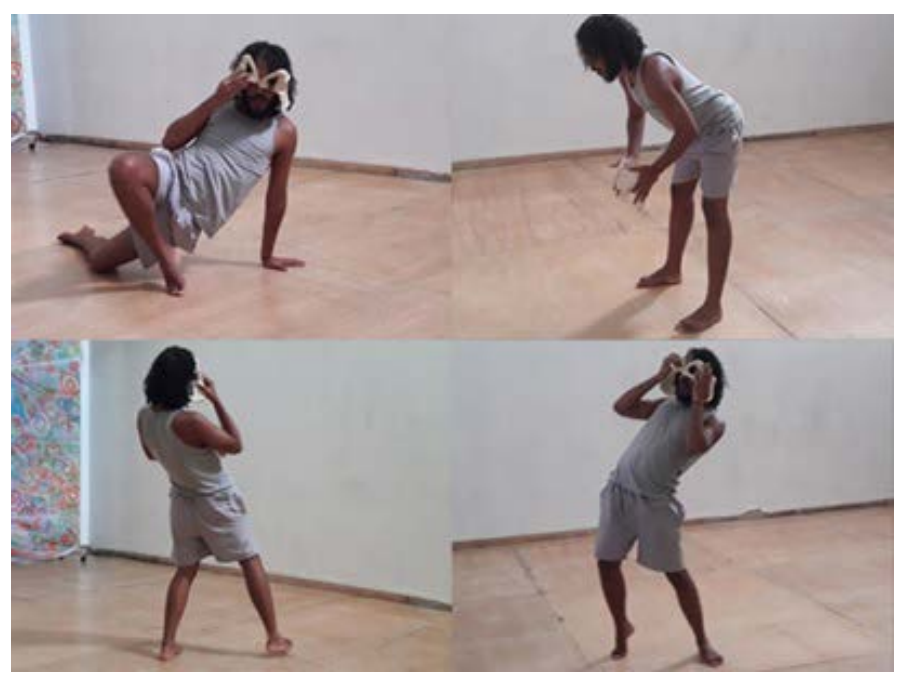

Fonte: Arquivo pessoal

Nas fotos anteriores são apresentadas algumas investigações sobre a relação entre a pelve do artista-pesquisador e a sua relação com a cruz tridimensional e também a cruz diagonal de Rudolf Laban. Paralelo ao estudo de espaço, foi utilizada também uma prótese da pelve em resina durante estes momentos de investigação de movimento. Como pode perceber-se nas fotografias apresentadas, há três delas em que a cavidade do forame obturador da pelve em resina plástica foi colocada sobre os olhos do artista-pesquisador e se delineou naquele momento uma pergunta poética: seria possível olhar com o forame obturador da própria pelve do corpo do artista-pesquisador para diferentes direções no espaço?
Este dispositivo de criação levou a diferentes possibilidades de torções do tronco, com o movimento sendo liderado por estas cavidades da pelve. A metáfora do forame obturador olhando para o espaço liderou o movimento do artista-pesquisador deste artigo durante os laboratórios de investigação. A partir dos diferentes ossos que compõem a estrutura de sua pelve foi possível estimular a plasticidade de um corpo retorcido, que se integrou à futura criação cênica.

Tais aspectos tematizaram os improvisos voltados para a elaboração do solo teatral, com o intuito de gerar temas restritos que ampliaram as possibilidades de experimentações. Com isso, emergiram os materiais necessários para a criação da futura cena teatral. Sobre a relação entre temas restritos de improvisação partindo do corpo e pesquisa criativa em artes cênicas, Sônia Machado de Azevedo reflete:

\begin{abstract}
Se a improvisação corporal for pensada como caminho aberto à experimentação livre de certos temas de movimento, e se essa experimentação constar de, por um lado, uma limitação objetivada nesses mesmos temas, e, por outro, uma criação imaginária de contextos e situações, o intercâmbio entre a mente e o corpo solidifica-se no trabalho. Um eixo claro em torno do qual se pode buscar tantas variáveis quantas forem desejadas, onde o canal que liga ideias e sua concretude física possa ser exercitado, até o ponto em que já não será possível separar o que é causado por um ou por outro: impulso e forma canalizam-se mutuamente, tendo como resultado a pesquisa criativa. (Azevedo, 2002, p. 268 e 269)
\end{abstract}

A partir das experimentações corporais com liderança da pelve do artista-pesquisador surgiram inspirações, que foram posteriormente desenvolvidas no solo teatral "Caminho do Meio". 
Apresentaremos a seguir um dos resultantes criativos da pesquisa a partir da pelve. Após esculpi-la, se tocar tendo como base o sistema de ossos ilíaco/púbis/sacro e, posteriormente, se mover com liderança da pelve, houve um processo de escrita de um texto, de autoria do próprio artista-pesquisador. Gradualmente incorporado à pesquisa teatral, este texto foi nomeado como "Pense no Parto", quando o artista-pesquisador foi imbuído por estímulos propostos a partir da fisicalidade da pelve. Apresentamos abaixo a primeira parte do texto elaborado, para posterior reflexão:

\author{
Pense no parto \\ Pense no parto \\ Pense no parto \\ Centro \\ Onde se começa \\ De onde... Fui gerado \\ Saí para habitar \\ Existir fora \\ Pense no parto \\ Criar vida \\ Mistura de pensamentos \\ Começo \\ Pensei na pelve \\ Pensei na pelve \\ Pensei na pelve \\ Na pelve da minha mãe
}

As palavras que resultaram no texto apresentado anteriormente foram decorrentes de alguns processos, como: o da sensibilização da pelve e também da rotina dos movimentos pesquisados e improvisados durante todo o processo artístico em sala de ensaios. Da escultura em argila para os momentos de sensibilização; do toque nos ossos às experimentações a partir dos movimentos; dos movimentos no corpo ao processo refinado de propriocepção. Todo este encaminhamento artístico aqui relatado trouxe sensações, lembranças e atualizações de memórias - muitas delas extre- mamente pessoais e que transbordaram no texto, como apresentamos em sua continuação abaixo:

$$
\begin{aligned}
& \text { Minha pelve } \\
& \text { Minha mãe } \\
& \text { Pense no parto } \\
& \text { Falar com a mãe } \\
& \text { Minha pelve } \\
& \text { Movimento } \\
& \text { Corpo } \\
& \text { Memória } \\
& \text { Criar vida }
\end{aligned}
$$

Da pelve esculpida à pelve percebida, até chegar à pelve materna descrita em palavras. Um longo processo foi desenvolvido para que o texto apresentado anteriormente fosse escrito. Resultante do processo artístico relatado neste artigo, tal texto ganhou novos sentidos, quando um depoimento pessoal do pesquisador sobre a morte de sua mãe foi ali incorporado e cuja narrativa será apresentada abaixo:

\section{Minha mãe se chamava Maria Anália Cardoso \\ Morreu no ano de 2001, aos 53 anos, na época eu tinha 13. \\ Neoplasia Uterina: câncer no útero}

\section{Útero}

\author{
Pense no parto \\ Órgão pélvico \\ Criar vida \\ Acontecimentos que o tempo apaga \\ Potencializa \\ Lembrei do dia em que foi realizada a \\ exumação de seu corpo \\ Ossos \\ A decisão dos filhos foi queimar os \\ ossos
}

Minha mãe

Gostaríamos de refletir e embasar brevemente como o trabalho proveniente do corpo (especialmente da pelve) foi elemento 
propulsor da atualização de memórias pessoais do artista-pesquisador, que desembocaram na elaboração do texto apresentado anteriormente. Fruto de uma pesquisa qualitativa e processual no campo das artes cênicas, encontramos no pensamento de Maria Fonseca Falkembach (2005, p. 21), a possibilidade do desenvolvimento criativo a partir do corpo. Falkembach reflete que há um texto corporal e que pode ser a concretização de um projeto poético do ator-dançarino. Para alcançar este projeto poético, Falkembach reflete que é:

Fruto de um trabalho técnico sobre si mesmo, capaz de relacionar a sensibilidade, o fluxo de sentimento e a expressão consciente, tal concretização do projeto poético acontece no corpo. O ator-dançarino, poeta de si mesmo, persegue o estético (o admirável, desejável em e por si mesmo), busca o conhecimento dos sentimentos humanos por meio do seu processo de criação, portanto, no rastro de suas ações cênicas, no modo como vai inscrever no espaço cênico a aparência teatral de seu corpo em movimento. (Falkembach, 2005, p. 21)

A partir do trânsito entre os impulsos provenientes do corpo e da ação de redigir um texto através das palavras, gostaríamos de apresentar como o fluxo entre investigação corporal e texto escrito foi gradualmente integrado à pesquisa em arte e narrada neste momento.

No processo de composição, o texto escrito transformou-se gradualmente na fala da primeira cena do solo teatral "Caminho do Meio", um dos resultantes apresentados neste artigo. Para a compreensão deste processo, apresentaremos a seguir uma composição de fotos da cena elaborada pelo artista-pesquisador em conjunto com uma foto de um trecho do diário de bordo elaborado, para posterior reflexão.
Figura 5 - Composição de fotos: Em destaque artista-pesquisador durante ação teatral. Abaixo e em sobreposição: trecho do texto registrado no diário de bordo. Fotos: Marcos Junior Valadão.

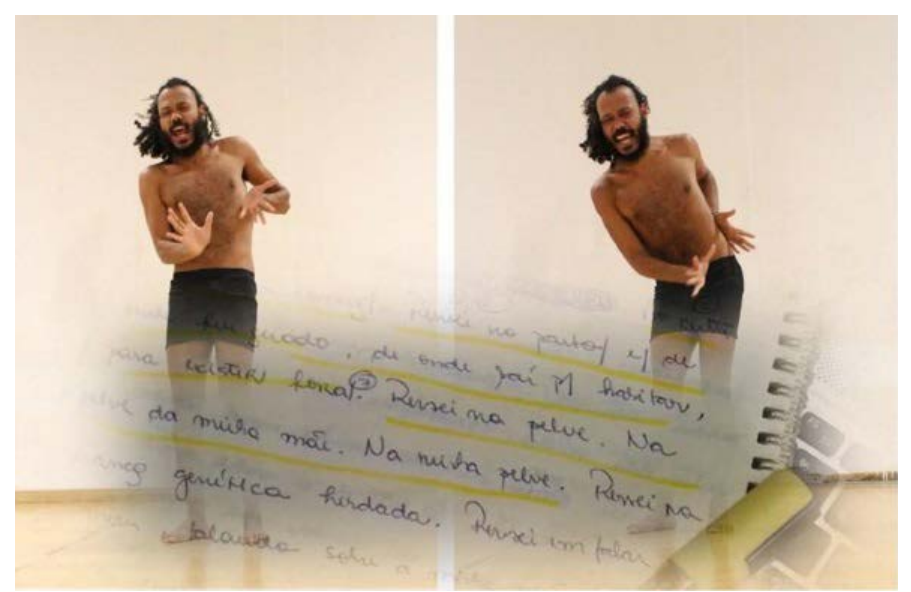

Fonte: Arquivo pessoal.

Gostaríamos de refletir sobre as imagens anteriormente apresentadas, que representam uma parcela do projeto poético que gradualmente se instaurou no processo artístico narrado neste artigo. Minuciosamente pesquisado na sala de ensaios, o texto escrito foi gradualmente integrado à relação entre e voz e movimento, cuja liderança era sempre realizada através do direcionamento da pelve. Através do processo do fazer teatral, o artista-pesquisador integrou $o$ texto escrito ao texto corporal, trazendo novos sentidos dramatúrgicos para a cena que estava sendo composta naquele momento da investigação.

Rigoroso, o processo de ensaios partia da sensibilização da pelve. Posteriormente, integrava os direcionamentos desta porção corporal à relação com espaço e também à experimentação entre voz e movimento. Após este percurso de pesquisa, anotações eram realizadas a partir do que foi investigado em sala de ensaios e foi possível arquitetar e registrar uma partitura corporal integrada ao texto escrito.

Abaixo apresentamos a continuidade da narrativa escrita, mas agora em formato de tabela. O texto será apresentado à es- 
querda e suas respectivas partituras corporais à direita.

Tabela 1 - Texto escrito e partitura corporal da cena "Pense no Parto".

\begin{tabular}{|c|c|}
\hline Texto & Partitura Corporal \\
\hline $\begin{array}{c}\text { Ossos } \\
\text { A decisão dos filhos foi de } \\
\text { queimar os ossos }\end{array}$ & $\begin{array}{l}\text { - Pausa } \\
\text { - Nível alto }\end{array}$ \\
\hline $\begin{array}{l}\text { Na medida em que o } \\
\text { coveiro recolhia os ossos, } \\
\text { e os colocava dentro de } \\
\text { um saco de lixo preto, era } \\
\text { como se uma boneca } \\
\text { fosse sendo desmontada }\end{array}$ & $\begin{array}{l}\text { - Movimento } \\
\text { sinuoso com os } \\
\text { ilíacos direito e } \\
\text { esquerdo em } \\
\text { direção às } \\
\text { diagonais } \\
\text { - Tempo súbito } \\
\text { - Nível alto }\end{array}$ \\
\hline $\begin{array}{c}\text { Saco de lixo preto } \\
\text { Ossos } \\
\text { Útero } \\
\text { Peso } \\
\text { Braços } \\
\text { Saco de lixo preto } \\
\text { Ossos } \\
\text { Útero } \\
\text { Peso } \\
\text { Braços } \\
\text { Saco de lixo preto }\end{array}$ & $\begin{array}{l}\text { - Movimento } \\
\text { sinuoso com os } \\
\text { ilíacos direito e } \\
\text { esquerdo em } \\
\text { direção às } \\
\text { diagonais } \\
\text { - Tempo súbito } \\
\text { - Nível alto }\end{array}$ \\
\hline $\begin{array}{c}\text { Aos } 16 \text { anos, } \\
\text { carreguei nos braços } \\
\text { o que restou do corpo } \\
\text { daquela mulher }\end{array}$ & $\begin{array}{l}\text { - Pausa } \\
\text { - Nível alto }\end{array}$ \\
\hline
\end{tabular}

A tabela apresentada anteriormente narra algumas propostas de relação entre texto e movimento, cuja composição dramatúrgica é refletida neste artigo. Ao observá- la é possível identificar as indicações para a realização do movimento e perceber eventuais ações em conjunto com o texto falado. Neste caso, o texto e a partitura corporal não devem ser considerados hierárquicos entre si, pois houve uma retroalimentação constante entre texto e movimento, o que ampliou os sentidos dramatúrgicos durante a construção da cena.

Entender a criação artística como sucessão do processo de pesquisa torna-se aprendizado e faz parte da formação do ator. Portanto, é necessário o compartilhamento de algumas considerações a respeito das etapas de investigação em arte realizadas e apresentadas neste artigo.

\section{Processo em suspensão: o meio como elemento mobilizador para o ator}

\author{
Fiz questão de seguir o caminho inteiro \\ abraçado aos ossos. \\ Eu carreguei os seus ossos até aqui. \\ $E$ hoje eu me pergunto: qual parte do \\ meu corpo tocava a sua pelve? \\ Pense na pelve. \\ Pense no parto ${ }^{11}$.
}

Após debruçar um ano sobre a pesquisa da pelve, alguns procedimentos de pesquisa em arte foram interligados, como a escultura em argila integrada a processos de autossensibilização corporal e a investigação poético-criativa entrelaçadas à criação de um texto autoral. Tais processos de pesquisa artística reverberaram no processo de desenvolvimento pessoal como ator e permitiram que o movimento ocorresse a partir da relação entre a pelve e outras partes do corpo. Tal foco fez com que se desenvolvesse uma reverberação da ação corporal e também que tal acontecimento fosse uma sucessão natural da estrutura esquelética, de modo que favoreceu o artista-pesquisador no entendimento do seu próprio corpo.

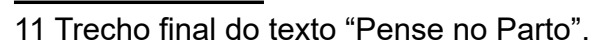


Faz parte dessa conscientização o ato de sensibilização, que deve ser considerada como uma etapa importante dentro do processo criativo e de reconhecimento do corpo do ator, como um ato de "despertar" constante.

Com o reconhecimento anatômico há um direcionamento mais consciente do corpo, que reverbera no processo de preparação cênica. Há uma incorporação gradual de repertórios, o que expande a qualidade expressiva do ator.

Até o início desta investigação, o primeiro autor deste artigo partia do texto para o movimento e com essa pesquisa pôde realizar o caminho inverso. $O$ texto foi acrescido no final do processo e surgiu como resposta às provocações que os movimentos investigados da pelve geraram. Inquietações, estímulos, dificuldades e reflexões manifestaram-se também por meio das palavras e ganharam outro espaço, através do texto redigido durante o processo apresentado neste artigo.

O impulso vindo da investigação corporal ganhou forma através do movimento. Transformado em palavra posteriormente, este ato renutriu a ação de se mover, como um ciclo de fluidez constante.

Considera-se a presente pesquisa como semente, que seguirá germinando no território do corpo dos autores deste artigo, em forma de corpo-signo, corpo cênico, corpo poético. Portanto, as influências causadas por esse estudo apontam para um trajeto de continuidade. Algumas perguntas foram respondidas e uma questão nova desabrochou: seria possível replicar o processo vivenciado para outros atores?

Tal pergunta move os autores deste artigo a manterem presente a vontade de continuarem pesquisando as estruturas ósseas a partir da investigação corporal e poética. Interessa aos autores deste artigo a fluidez da criação artística, de forma a compreenderem a poética corporal como uma sucessão constante de investigação de movimento. $\mathrm{Na}$ formação de atores, consideramos que a fluidez de tais criações dentro da poética corporal é como um recorte vivo de um sistema integrado, em que uma parte não apenas interfere, mas transmuta o todo.

\section{Referências}

AZEVEDO, Sônia Machado de. O papel do corpo no corpo do ator. São Paulo: Perspectiva, 2002.

BONFITTO, Matteo. O ator compositor: as ações físicas como eixo: de Stanislávski a Barba. São Paulo: Perspectiva, 2002.

FALKEMBACH, Maria Fonseca. Dramaturgia do corpo e reinvenção de linguagem: transcrição de retratos literários de Gertrude Stein na composição do corpo cênico. Dissertação (mestrado em Artes). Universidade do Estado de Santa Catarina, Florianópolis, 2005.

LABAN, Rudolf. Domínio do Movimento. $5^{\mathrm{a}}$ ed. São Paulo: Summus, 1978.

MACHADO, Maria Marcondes. O diário de bordo como ferramenta fenomenológica para o pesquisador em artes cênicas. Sala Preta, Brasil, v. 2, p. 260-263, nov. 2002. ISSN 2238-3867. Disponível em: <https://www.revistas.usp.br/salapreta/article/view/57101>. Acesso em: 03 de maio de 2018. doi:http://dx.doi.org/10.11606/issn.2238-3867. v2i0p260-263.

MILLER, Jussara. A escuta do corpo- sistematização da técnica Klauss Vianna. $2^{\mathrm{a}}$ ed. São Paulo: Summus, 2007. 
NEVES, Neide. O movimento como Processo Evolutivo Gerador de Comunicação - Técnica Klauss Vianna. Dissertação (Mestrado). Pontifícia Universidade Católica, São Paulo, 2004.

RENGEL, Lenira Peral. Dicionário Laban. Dissertação (mestrado em Artes). Universidade Estadual de Campinas, São Paulo, 2001.

ROMANO, Lúcia. O teatro do Corpo Manifesto: teatro físico. São Paulo: Perspectiva, 2008.

VIANNA, Klauss; CARVALHO, Marco Antonio de. A Dança. São Paulo: Summus Editorial, $7^{\mathrm{a}}$ ed., 2005.

Recebido: 29/06/2018 Aprovado: 16/07/2019 